\title{
Bone loss in spinal cord-injured patients: from physiopathology to therapy
}

\author{
L Maïmoun*,1,2, C Fattal ${ }^{1}$, J-P Micallef ${ }^{3}$, E Peruchon $^{3}$ and P Rabischong ${ }^{1}$ \\ ${ }^{1}$ Centre Mutualiste Neurologique Propara, Montpellier, France; ${ }^{2}$ Groupe de Recherche Interdisciplinaire Sur le \\ Métabolisme Osseux (GRISMO), Montpellier, France; ${ }^{3}$ INSERM, Montpellier, France
}

Study design: Review article on bone metabolism and therapeutic approach on bone loss in patients with spinal cord injury (SCI).

Objective: The first part aims to describe the process of bone demineralization and its effects on bone mass in patients with SCI. The second part describes and discusses the therapeutic approaches to limiting the alteration in bone metabolism related to neurological lesions.

Setting: Propara Rehabilitation Center, Montpellier, France.

Results: During the first 24 months postinjury, demineralization occurs exclusively in the sublesional areas and predominantly in weight-bearing skeletal sites such as the distal femur and proximal tibia, both of which are trabecular-rich sites. Reduced bone mass, in association with a modified bone matrix property and composition, is very likely at the origin of pathological fractures after minor trauma to which these patients are frequently exposed. Since these fractures may be asymptomatic yet may lead to complications, preventing and managing 'neurological osteoporosis' remains a considerable challenge. Two main approaches are considered: the first consists in applying a mechanical stimulus to the bone tissue by standing, orthotically aided walking or functional electrical stimulation (FES). The second uses medications, particularly antiresorptive drugs such as calcitonin or diphosphonates.

Conclusion: To develop well-adapted treatments, a more precise understanding of bone loss etiology is needed. The current rehabilitation programs are based on the idea that the bone physiological changes observed in patients with SCI are due to immobility, but results indicate that alterations inherent to neurological damage may play an even greater role in inducing osteoporosis. Spinal Cord (2006) 44, 203-210. doi:10.1038/sj.sc.3101832; published online 13 September 2005

Keywords: patients with spinal cord injury; bone loss; therapeutic approach; calcium homeostasis; disphosphonates

\section{Introduction}

Spinal cord injury (SCI) has wide-ranging psychological and pathological effects, these last including an increase in bone resorption, ${ }^{1-3}$ hormonal alterations ${ }^{4-6}$ and modification of body composition. ${ }^{7,8}$ The annual incidence of SCI differs according to the source but ranges from approximately 28.5 to 40 cases per million population. ${ }^{9,10}$ Quadriplegia resulting from injury of the cervical spinal cord represents $56 \%$ of the cases, whereas paraplegia resulting from injury of the thoracic, lumbar, or sacral regions represents $44 \% .^{9}$ The most frequent cause of injury is mainly traffic accidents (43$50 \%$ ), followed by falls, sports accidents, and acts of violence. ${ }^{9,10}$ Male patients are about four times as numerous as females ${ }^{9,10}$ and the incidence of lesions is the highest in the 15-24-year group for both genders. ${ }^{911}$

*Correspondence: L Maïmoun, Centre Mutualiste Neurologique Propara, Parc Euromedecine, 263, rue de la Caducée, 34195 Montpellier, France
The mean age at the time of injury ranges from 27 to 32.4 years for males and from 31 to 35.4 years for females. ${ }^{9,12}$ Since the incidence of SCI is highest among young people ${ }^{9}$ and the life expectancy of these patients has increased dramatically since the Second World War, ${ }^{12,13}$ strategies to prevent certain pathologies known to accentuate disability are necessary. Moreover, the future prospects of restoring mobility to these patients are strong encouragement to maintain the original qualities of both muscle and bone tissue. The clinical approaches to limiting the alterations in bone metabolism related to neurological lesions will be described and discussed from a physiopathological perspective.

\section{The physiopathological context}

Osteoporosis is one of the major complications in patients with SCI. ${ }^{1,14}$ The neurological lesion and subsequent immobilization induce early and severe bone 
loss, ${ }^{11,15,16}$ especially in young adults. ${ }^{17}$ During the first months postinjury, demineralization occurs exclusively in the sublesional areas and predominantly in weightbearing skeletal sites such as the distal femur and proximal tibia, which are trabecular-rich sites, $3,11,15,18,19$ while the diaphyseal areas of the femur and the tibia, which are cortical-rich sites, are relatively spared. ${ }^{19}$ Using the dual energy X-ray absorptiometry (DEXA) technique, Wilmet et $a l^{7}$ reported a decrease in bone mineral content (BMC) during the first year postinjury of about $4 \%$ per month in areas rich in trabecular bone and $2 \%$ per month in areas containing mainly cortical bone. This clear dissociation of bone mineral density (BMD) loss between the trabecular and cortical compartments has been confirmed using the peripheral quantitative computed tomography (pQCT) technique. $^{20,21}$ This method showed that in the epiphysis, bone mass loss is related to BMD decrease, while in the shaft it is related to reduced cortical wall thickness by the process of endosteal resorption. ${ }^{21}$ Paradoxically, at the lumbar spine, which is mainly constituted of trabecular bone, no reduction in BMD occurs whatever the lesion level or postinjury duration. 1,3,11,16-18,22-31 This has been demonstrated to be due to continuous body weight-bearing during wheelchair use. 1,11,23,24 $^{-1}$ However, it should be kept in mind that in certain cases, BMD at the lumbar spine can be 'falsely increased' by neuropathic spondylopathy. ${ }^{32}$

The exact etiology of bone disturbance in SCI patients is not precisely known. The affecting factors may include a decrease in the mechanical force applied to bone, ${ }^{33,34}$ lesion-induced blood circulation abnormalities at the sublesional level that affect bone cell differentiation, ${ }^{35}$ and hormonal deficiencies. ${ }^{4-6,36}$ Moreover, the anatomical distribution of bone loss between axial and appendicular skeleton is unique compared with the endocrine causes of osteoporosis. ${ }^{16}$ Recently, our group reported a marked modification in the osteoprotegerin/ RANKL system in recent SCI patients. ${ }^{3}$ During the first months following injury, the releasing of the mineral phase modifies calcium homeostasis. ${ }^{37,38}$ Hypercalcemia and hypercalciuria, ${ }^{37-40}$ which lead to the development of renal calculi ${ }^{41}$ and to alterations in the calciotropic hormonal profile, $2,3,38,42-44$ are the most commonly encountered abnormalities. Histomorphometric data demonstrated that the principal cause of bone loss is the increase in bone resorption as defined by an augmentation in eroded surfaces and of the number of osteoclasts. ${ }^{14}$ The use of bone biochemical markers revealed that bone resorption continuously increases from the first weeks postinjury and peaks between weeks 10 and $16,{ }^{2,3,18,44,45}$ with values reaching up to 10 times the upper limits of normal. ${ }^{2}$ Moreover, after 1 year, the markers of bone resorption, such as hydroxyproline and deoxyproline, remain elevated. ${ }^{19}$ At the same time, bone formation markers show only a minor rise..$^{2,3,19,44,46}$ The imbalance between bone formation and bone resorption $^{2,46,47}$ is responsible for this bone loss, which begins just after injury and peaks 3-5 months later. $2,7,15,46$ From about 16-24 months postinjury, the bone meta- bolic process tends toward a new steady state, ${ }^{11,15,47}$ but various studies have indicated that BMD at different sites declines with increasing age and is inversely related to the time after injury, which indicates continuous bone loss beyond the first 2 years postinjury. ${ }^{17,21,27,48-50}$ In this relatively stable phase, high bone loss corresponding to $30-50 \%$ of the normal value, depending on the bone site and the age of the subject, has been reported. ${ }^{11,15,17,27}$ Bone loss at the lower limbs is independent of the lesion level, ${ }^{15,19,23,30,31,48,51}$ while bone loss at the upper limbs is observed only in tetraplegic patients. ${ }^{11,15,19,20,48,51,52}$ Consequently, the neurological level determines the extent, but not the degree, of the demineralization. ${ }^{15}$ In addition, bone alterations may be greater in SCI individuals with a complete lesion than in those who sustain incomplete lesions. ${ }^{18,28,48,53-55}$ The bone mass reduction associated with a modification of bone matrix composition ${ }^{45}$ and reduced bone elasticity ${ }^{56}$ is very likely at the origin of the pathological fractures after minor trauma to which these patients are frequently exposed. ${ }^{50,57,56}$ In a cross-sectional study, Szollar et $a l^{29}$ reported that bone loss was detectable by densitometry from 12 months postinjury in an age group ranging from 20 to 39 years and that the fracture threshold was reached from 1-9 years after SCI. Lazo et $a l^{50}$ showed that 25 out of 41 SCI subjects $(61 \%)$ met the World Health Organization (WHO) criteria for osteoporosis ( $T$-scores $>2.5 \mathrm{SD})$, eight $(19.5 \%)$ were osteopenic $(T$-scores $=1-2.5 \mathrm{SD})$ and only eight $(19.5 \%)$ showed normal values ( $T$-scores $\leqslant 1 \mathrm{SD})$. The incidence of fracture has been reported to be between 1 and $6 \%$ of the patients but is probably underestimated. ${ }^{56,58,59}$ Lazo et $a l^{50}$ also reported a higher frequency of history of fracture $(34 \%$ of patients). The predominance of bone demineralization at the distal femur or proximal tibia could explain why these areas are preferential fracture sites. ${ }^{60}$ The decrease in BMD is certainly the main causative factor. ${ }^{1,50,60,61}$ For example, a BMD decrease at the femoral neck of $0.1 \mathrm{~g} / \mathrm{cm}^{2}$ increased the risk of fracture by $2.2 .^{50}$ As these fractures are asymptomatic, induce complications (callus formation, pressure sores, increased spasticity, etc) ${ }^{56}$ and require long-term immobilization for treatment, preventing and managing osteoporosis remains a considerable challenge. Over the past few decades, many studies have investigated treatments to limit or reverse the degenerative process of osteoporosis. From the various experimental and clinical studies, two main therapeutic approaches have emerged. The first consists in applying a mechanical stimulus to the bone tissue and the second uses medications, particularly antiresorptive drugs.

\section{Rehabilitation-oriented approach}

A neurological lesion, with subsequent immobilization, leads to a dramatic reduction in muscle contraction and a redistribution of the gravitational forces applied to the skeleton, to the detriment of the bone segments that normally support body weight. To limit the bone loss resulting from this situation, a logical approach would 
be to develop rehabilitation techniques that mechanically restimulate the bone segments to return, as much as possible, to the prelesional physiological and biomechanical conditions.

\section{Standing-up and orthotically aided walking}

Among the factors inducing bone demineralization in SCI patients, reduced bone mechanical loading seems to be particularly determinant, as observed in such experimental conditions as prolonged bedrest ${ }^{33}$ or weightlessness. ${ }^{34}$ Moreover, Dauty et al ${ }^{19}$ demonstrated that the duration of the initial immobilization of SCI patients is the factor that most significantly affects BMD at the trochanteric area. Thus, early verticalization of the body could contribute to limiting initial bone demineralization. ${ }^{19}$ The maintenance of normal axial bone-loading by passive standing (standing frame or tilt table) or by various aided-walking systems has long been promoted as a therapy to reduce calcium losses and consequently to retard or reverse SCI-associated osteoporosis. ${ }^{62-64}$ However, in chronic patients, prolonged standing sessions ${ }^{1,24}$ or walking with a mechanical orthosis $^{25,65,66}$ have shown no significant effects on BMD. Kunkel et $a l^{24}$ reported that 6 months of using a standing frame for $45 \mathrm{~min}$ twice a day did not lead to noticeable bone gain at the femoral neck nor to an increase in bone formation markers. It should nevertheless be noted that this experiment was performed in six chronically paralyzed men (ie, postlesional duration $>10$ years). Needham-Shropshire et $a l^{66}$ used the 'Parastep ${ }^{\circledR} 1$ ' ambulation device, which combines a modified walker with functional electrical stimulation (FES). They reported no BMD change in the femur after 20 weeks of rigorous rehabilitation performed by 16 individuals with SCI having a mean postinjury duration of 3.8 years.

This type of intervention seems to have a favorable effect only during the early postlesional phase. Prolonged standing sessions (tilt-table) combined with exercise have been shown to reduce hypercalciuria. ${ }^{63,64}$ Goemare et $a l^{67}$ reported that subjects regularly performing passive weight-bearing standing, from 1 year post-injury, showed less BMD decrease at the femoral shaft. In addition, De Bruin et $a l^{68}$ reported no or insignificant loss in tibia trabecular bone in patients participating in standing-up sessions during the first 25 weeks after injury, whether associated with treadmill walking or not (1 h per day, 5 days per week). In any case, these findings were not confirmed in patients with a postlesional duration of less than 4 weeks who participated in similar physical training sessions (standing and walking). ${ }^{20}$ Moreover, Frey-Rindova et $a l^{20}$ underlined the motivational and health problems that arise during the execution of such training programs. Other investigations were unable to show any preventive effect of active or passive verticalization on bone demineralization as well. ${ }^{19,28,30}$ Through these different experiments, it thus appears that verticalization alone is not a sufficient therapeutic means to prevent bone demineralization, although it may limit it. Early verticalization continues to be recommended to alleviate the deleterious effects of the initial bedrest period on the lower limbs. ${ }^{19}$ The limited effect of such training programs is probably partly due to the static nature and the reduced level of the mechanical constraints effectively applied to bone structures compared with the constraints developed during normal gait. Indeed, both clinical and experimental studies have demonstrated that dynamic loading is more effective than static loading in terms of bone accretion. ${ }^{69}$ Consequently, the association of standing-up with techniques generating constraint variations, such as the use of vibrating frames, should accentuate the effectiveness of the treatment. This can be illustrated by the recent findings of Rubin et $a l,{ }^{70}$ who demonstrated an increase in the quality and quantity of trabecular bone in sheep exposed to low-level, high-frequency mechanical stimuli. Similarly, a significant increase in hip bone mineral density and muscle strength was observed in postmenopausal women after 6 months of whole body vibration. ${ }^{71}$ Overall, these experiments suggest the potential clinical relevance of vibration-loading to prevent and treat osteoporosis in SCI patients. However, to this date, the relevance and efficacy of this technique has not been evaluated in the SCI population.

\section{Physical exercise}

In the able-bodied population, exercise has been shown to have an osteogenic influence on bone sites submitted to weight-bearing or impact. ${ }^{72}$ In highly active SCI patients, Jones et $a l^{31}$ reported that upper limb bone mass is preserved while a significant demineralization can be noted in the lower body. The beneficial effect at the upper limbs was observed whatever the level of lesion and even in tetraplegic individuals who have been reported to be at risk for demineralization at these sites. ${ }^{11,15,19,20,48,51,52}$ Jones's et al's ${ }^{31}$ findings confirmed the assumption that intensive exercise such as skiing, quad rugby, wheelchair basketball, and weight-training have a localized and not a systemic beneficial effect on the skeleton. The idea that mobility may contribute to preserving bone density was previously reported by Saltzstein et al. ${ }^{53}$ These authors measured distal tibia bone density in $27 \mathrm{SCI}$ subjects grouped according to the completeness of the lesion, and also according to a 'mobility index' that ranked the ability of subjects to ambulate. They found lower average bone density in subjects with complete motor lesions than in subjects with incomplete lesions and able-bodied controls. Moreover, bone loss was correlated with the subject's 'mobility index'. These data suggest that bone loss in SCI patients can be limited by the practice of weightbearing activities introduced in therapeutic routines. ${ }^{53}$

\section{Functional electrical stimulation}

Muscular FES ${ }^{73,74}$ has generally been used to minimize the muscle atrophy that occurs after a neurological 
lesion. $^{8}$ In addition, since FES results in muscle contraction and thus tension on the skeleton, various authors have hypothesized that FES-induced mechanical loading might contribute to preserving bone mass in patients with SCI. Several training modalities have been investigated with FES alone or in association with hybrid lower extremity cycle ergometer exercise (ie, REGYS I). In patients trained $1 \mathrm{~h}$ daily by FES of the quadriceps, a significant increase in BMD was observed at the distal femur $(11.1 \%)$ and at the proximal tibia $(9.7 \%)$, but interestingly not at the mid-tibia. ${ }^{75}$ The distal femur and proximal tibia correspond to the anatomical insertions of the stimulated muscle where forces are effectively applied and concentrated. ${ }^{27,75}$ These findings are in line with those of Bloomfied et $a l^{76}$ and Mohr et $a l^{27}$ and, although the beneficial effect seems to be localized at the mechanically strained bone sites, bone gain in these specific regions is essential, since most of the lower extremity fractures are supracondylar. ${ }^{58,60} \mathrm{BMD}$ at the distal tibia nevertheless remains low in comparison with normal values and it is thus unlikely that the fracture risk in patients can be substantially changed. ${ }^{76}$ Moreover, the bone mass gain decreased when FES training was reduced. ${ }^{27}$

The expected favorable effect of FES has nevertheless not been confirmed by most 3-12-month FES programs, whether or not they were associated with cycling or assisted walking. ${ }^{22,26,66,77-80}$ Rodgers et $a l^{78}$ used electrical stimulation of the quadriceps muscles in a knee extension exercise and reported that the bone density at the tibia remained unchanged despite improved muscle performance. The differences in training program characteristics (session frequency, training duration, and intensity) might explain these inconsistent findings. ${ }^{27,76,81}$ Similarly, Bloomfield et $a l^{76}$ found a BMD increase of $17.8 \%$ over 9 months in the distal femur in a subset of patients developing a minimum of $18 \mathrm{~W}$ on a REGYS I system. Mohr et $a^{27}$ observed that 12 months of FES-assisted cycling increased the BMD at the proximal tibia by $10 \%$, but the bone mass gain was not conserved after 6 months with reduced-frequency exercise. These data suggest a bone stimulation threshold related to the physical features of the training program. Moreover, the postinjury duration also seems to be a determinant parameter of the bone response, because no significant bone gain could be seen in patients starting the training program 13.5 years after the lesion. ${ }^{75}$ Another possible explanation for the discrepant results could be the specific responsiveness of the skeletal region being analyzed. ${ }^{75}$ As mentioned above, the proximal tibia and the distal femur ${ }^{27,75,76}$ seem to be more responsive to mechanical loading than the femoral neck. ${ }^{26,75,76}$ In SCI patients particularly, this bony site is strongly affected by bone degeneration. $1,3,11,17,19$ Whatever the training protocol used, however, no change in BMD at this site has been reported, ${ }^{26,27,66,76,77}$ probably because the mechanical load exerted at the femoral neck during FES-assisted cycling $^{76}$ or FES-assisted walking exercise ${ }^{66}$ does not reach the required bone mechanical threshold. An additional explanation could be the lack of muscle attachments at this site.

Few studies have investigated the response of the bone markers of bone turnover to FES and the results remain controversial. ${ }^{27,76}$ Bloomfield et $a l^{76}$ found a dramatic increase of $78 \%$ in serum osteocalcin (OC) levels after the first 6 months of training, with values maintained for up to 9 months, while Mohr et $a l^{27}$ reported no changes in OC after 12 months. No modification in the markers of bone resorption, that is, hydroxyproline ${ }^{76}$ or deoxypyridinoline, ${ }^{27}$ was observed in either study. It is probable that the bone mass gain was too small to cause measurable systemic changes in bone markers. $^{27}$

These experiments indicate that well-controlled muscle FES can have a positive effect on BMD. However, this effect remains localized to specific bone sites and total recovery of bone mass has never been demonstrated. Nevertheless, most of the results concerned chronic SCI subjects (postlesional time $>1.5$ year) in which bone loss had already reached a significant level. Minaire $^{82}$ suggested that the possibility for bone recovery may disappear 6 months postinjury. Eser et $a l^{81}$ investigated the effect of 6 months of FES cycling in recent SCI patients (postlesional duration 4.5 weeks). The mean BMD decrease in the training group was only half the monthly decrease in the control group, but the difference was not statistically significant. NeedhamShropshire et $a l^{66}$ reported that early intervention (7 months postinjury) might not be effective in preventing osteoporosis but suggested that earlier intervention might limit bone loss. ${ }^{66}$

\section{Low-intensity pulsed ultrasound}

In vitro and in vivo studies have demonstrated that lowintensity pulsed ultrasound (US) might constitute an osteogenic stimulus. ${ }^{83,84}$ Recently, Warden et al ${ }^{85}$ applied specific US at the calcaneum for 6 weeks in young subjects with 1-6-month histories of complete SCI. The results showed that low-intensity pulsed US was unable to protect against SCI-induced calcaneal bone demineralization. Further investigations are needed.

\section{Pharmacological treatment}

The physiopathological data have shown that bone demineralization in patients with SCI can be principally attributed to an alteration of the bone remodeling process that dramatically favors an increase in bone resorption. Drug treatment thus mostly consists of substances that inhibit osteoclast cell activity.

\section{Calcitonin}

Calcitonin is a potent inhibitor of bone resorption that acts directly both on osteoclasts to inhibit mobility, number, and secretion activity ${ }^{86}$ and on osteoclast precursors to prevent their fusion. ${ }^{87}$ In the last three decades, calcitonin has been used in postmenopausal 
women to prevent bone $\operatorname{loss}^{88}$ and reduce pathological fractures. ${ }^{89}$ Transcutaneous injection or intranasal intake of salmon calcitonin has been reported to limit immobilization hypercalcemia and hypercalciuria, ${ }^{40,90,91}$ to reduce osteoclast activity, ${ }^{90}$ and to preserve trabecular bone volume. ${ }^{90}$ But a high incidence of nausea and the frequency of injections seem to limit patient compliance. ${ }^{40}$ Calcitonin may temporarily reduce immobilization hypercalcemia and this short-lasting effect may be due to the well-known 'escape' phenomenon. ${ }^{92}$ Contrasting with these results, Maynard ${ }^{40}$ reported no resistance to salmon calcitonin over 2-4 months of treatment. The combination of etidronate (bisphosphonates) $(1600 \mathrm{mg} /$ day) and salmon calcitonin (200 IU/ day) rapidly reduced the hypercalcemia and hypercalciuria with a minimum of side effects. ${ }^{93}$ However, the optimal dosage and long-term effectiveness of calcitonin treatment remain unclear.

\section{Bisphosphonates}

Bisphosphonates are extremely potent inhibitors of bone resorption and soft tissue calcification. Different mechanisms of action are involved, including physicochemical, cellular, and/or biochemical processes. As bone loss in SCI patients is principally due to an increase in bone resorption, ${ }^{2,3}$ bisphosphonates, which are selective inhibitors of osteoclastic activity, should be a promising therapeutic approach. Bisphosphonates have been used for more than two decades in the treatment of SCI-induced osteoporosis and most of the results tend to show a reduction in hypercalcemia and bone loss. In recent SCI patients treated with clodronate (400 or $1600 \mathrm{mg} /$ day), Minaire et $a l^{39}$ found marked reduction of hydroxyproline, and serum and urine calcium levels. In clodronate-treated patients, no further decrease in BMC at the lower end of the tibia was demonstrated, whereas BMC decreased in controls. Nevertheless, as suggested by the increase in the number of osteoclasts as evaluated by histomorphometry, it is probable that the major changes in trabecular bone mass had already occurred before treatment (mean 17.6 days; range 5-29). Pearson et $\mathrm{l}^{28}$ reported the favorable effect of etidronate, a first-generation bisphosphonate, used in cyclic treatment $(800 \mathrm{mg}$ daily) of patients 6 weeks postinjury. However, lower limb bone density was preserved over time only in selected etidronate-treated walking patients, whereas it decreased in the etidronatetreated wheelchair patients. The protective effect of walking itself was nevertheless not observed in the control patients, however, and the authors speculated that the combination of osteoclast depression due to cyclical etidronate application and osteoblastic activation due to weight-bearing activity may have maintained the BMD level. Interestingly, although the treatment was administered over the first 30 weeks, the protective effect of etidronate was maintained 1 year after SCI.

Newer bisphosphonates such as tiludronate, pamidronate, and alendronate are respectively 10, 100, and 1000 times more potent than etidronate. High doses of tiludronate $(400 \mathrm{mg} /$ day $)$ produced a slight increase in the bone volume/total volume ratio in the transiliac bone. ${ }^{94}$ A single 30 or $40 \mathrm{mg}$ infusion of pamidronate reduced hypercalcemia in patients unsuccessfully treated with calcitonin. ${ }^{92}$ The level of serum calcium decreased rapidly within 6-8 days ${ }^{91,92}$ and then was maintained for several weeks. ${ }^{92}$ Intravenous pamidronate treatment $(30 \mathrm{mg} \text {, every } 4 \text { weeks })^{18}$ reduced the bone mass loss as well as the excretion of the urinary bone-breakdown product, $\mathrm{N}$-telopeptide (marker of bone resorption), in patients with a recent lesion. As previously reported, ${ }^{28}$ ambulatory treated subjects showed less bone alteration than nonambulatory treated subjects. Moreover, Sniger and Garshick ${ }^{95}$ reported a favorable effect on BMD at the lumbar spine and in the lower extremities of a chronic patient with Brown-Sequard's injury treated for 24 months with alendronate $(10 \mathrm{mg} / \mathrm{day})$ plus vitamin $\mathrm{D}$ and calcium carbonate and performing weight-bearing activities. In that case, BMD was improved preferentially in the more osteoporotic leg. All these results suggest that the effect of drug treatment would depend on the ambulatory ability of the patient. ${ }^{18,28,95}$

Although the efficacy of these agents seems to be real, it has been difficult until now to draw definitive conclusions about their effects on bone mass, given the generally small size of the subject samples and the short durations of treatment. In a very recent investigation with a large group of men with complete paralysis $(n=29)$, Zehnder et $a l^{96}$ highlighted the favorable effect of long-term bisphosphonate treatment. In this study, a sub group was treated daily with alendronate $10 \mathrm{mg}$ associated with elemental calcium $500 \mathrm{mg}$. The BMD measured at cortical or trabecular infralesional bone sites was preserved 24 months later, while in the subgroup treated with calcium only, BMD was significantly reduced. However, although bone loss was stopped and the parameters of bone turnover were reduced after alendronate treatment, BMD at the infralesional sites was significantly lower than normal values. The choice of 10-year postinjury patients, in whom bone loss was already present, might explain the low level of BMD.

The newest generation of bisphosphonates, such as ibandronate and zoledronate, is 10000 times more potent than etidronate; these drugs are currently available and should be evaluated for application in SCI patients. Besides their beneficial effects on bone mass, bisphosphonates are generally well-tolerated without or with only mild adverse or side effects. ${ }^{18,28,91,96}$ They thus seem to be particularly well tailored for clinical applications in SCI patients.

\section{Conclusion and future prospects}

This work described the different clinical approaches to limiting the alteration of bone metabolism that follows a lesion of the spinal cord. We proposed two major classifications of treatment. The first includes all treatments based on the application of physical 
constraints on the bone material, ranging from active or passive verticalization and aided-walking systems to muscle FES, in order to offset the deleterious effects of immobilization. This approach, however, has led to rather disappointing results, possibly because of delayed treatment in chronic patients or the application of mechanical stresses insufficient to induce an osteogenic effect. The challenge is to apply sufficient levels of mechanical stimulus without increasing the risk of fracture in patients with reduced bone mass.

The second approach is pharmacological treatments. The bisphosphonates appear to be appropriate to reduce the intense bone resorption activity, especially during the acute phase of SCI when active rehabilitation programs cannot be carried out. The effectiveness of bisphosphonates to reduce bone loss has been demonstrated in both the early and chronic phases of the disease. The treatment in any case cannot stop the demineralization process. Pharmacological treatment of patients with SCI has generally been derived from those developed for postmenopausal women with osteoporosis. In fact, the physiopathological mechanisms that induce the osteopenia related to SCI are quite different. A specific posology or new drugs either associated or not with rehabilitation programs must be developed in the clinical field of SCI.

To develop well-adapted treatments, a more precise understanding of bone loss etiology is needed. The current rehabilitation programs are based on the idea that the bone physiological changes observed in patients with SCI are due to immobility. Yet a review of the literature indicates that alterations inherent to neurological damage may play an even greater role in inducing osteoporosis. Consequently, the term 'neurogenic osteoporosis' proposed by Bedell et $a l^{26}$ would better define the process of bone loss after SCI than 'immobilization osteoporosis' or 'disuse osteoporosis'. Moreover, the recent findings on the central control of bone mass contribute to clarifying the effect of a neurological lesion on bone alteration.

\section{References}

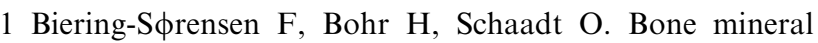
content of the lumbar spine and lower extremities years after spinal cord lesion. Paraplegia 1988; 26: 293-301.

2 Roberts D et al. Longitudinal study of bone turnover after acute spinal cord injury. J Clin Endocrinol Metab 1998; 83: 415-422.

3 Maïmoun L et al. Changes in osteoprotegerin/RANKL system, bone mineral density and bone biochemical markers in patients with recent spinal cord injury. Calcif Tissue Int 2005; 76: 404-411.

4 Shetty KR, Sutton CH, Mattson DA, Rudman D. Hyposomatomedinemia in quadraplegic men. Am J Med Sci 1993; 305: 95-100.

5 Bauman WA et al. Blunted growth hormone response to intravenous arginine in subjects with a spinal cord injury. Horm Metab Res 1994; 26: 149-153.

6 Maïmoun L et al. Androgens and growth factors are not associated to the bone resorption process in men with recent spinal cord injury: a cross-sectional study. Spinal Cord 2005 (in press).

7 Wilmet E, Ismail AA, Heilporn A, Welraeds D, Bergmann P. Longitudinal study of the bone mineral content and of soft tissue composition after spinal cord section. Paraplegia 1995; 33: 674-677.

8 Maïmoun L et al. Circulating leptin concentrations can be used as a surrogate marker of fat mass in acute spinal cord injury. Metabolism 2004; 53: 989-994.

9 Acton PA, Farley T, Freni LW, Ilegbodu VA, Sniezek JE, Wohlled JC. Traumatic spinal cord injury in Arkansas, 1980 to 1989. Arch Phys Med Rehab 1993; 74: 1035-1040.

10 Schingu H, Ohama M, Ikata T, Katoh S, Akatsu T. A nationwide epidemiological survey of spinal cord injuries in Japan from January 1990 to December 1992. Paraplegia 1995; 33: 183-188.

11 Biering-S $\phi$ rensen F, Bohr H, Schaadt O. Longitudinal study of bone mineral content in the lumbar spine, the forearm and the lower extremities after spinal cord injury. Eur J Clin Invest 1990; 20: 330-335.

12 Hartkopp A, Bronnum-Hansen H, Seidenschnur AM, Biering-Sorensen F. Survival and cause of death after traumatic spinal cord injury: a long-term epidemiological survey from Denmark. Spinal Cord 1997; 35: 76-85.

13 Ducker TB. Treatment of spinal cord injury. $N$ Eng J Med 1990; 322: 1459-1461.

14 Minaire P, Meunier PJ, Edouard C, Bernard J, Courpon P, Bourret J. Quantitative histological data on disuse osteoporosis, comparison with histological data. Calcif Tissue Int 1974; 17: 57-73.

15 Garland DE et al. Osteoporosis after spinal cord injury. J Orthop Res 1992; 10: 371-378.

16 Leslie WD, Nance PW. Dissociated hip and spine demineralization: a specific finding in spinal cord injury. Arch Phys Med Rehab 1993; 74: 960-964.

17 Szollar SM, Martin EME, Parthemore JG, Sartoris DJ, Deftos LJ. Densitometric patterns of spinal cord injury associated bone loss. Spinal Cord 1997; 35: 374-382.

18 Nance PW, Schryvers O, Leslie W, Ludwig S, Krahn J, Uebelhart D. Intravenous pamidronate attenuates bone density loss after acute spinal cord injury. Arch Phys Med Rehab 1999; 80: 243-251.

19 Dauty M, Perrouin-Verbe B, Maugars Y, Dubois C, Mathie JF. Supralesional and sublesional bone mineral density in spinal cord-injured patients. Bone 2000; 27: 305-309.

20 Frey-Rindova P, De Bruin ED, Stussi E, Dambacher MA, Dietz V. Bone mineral density in upper and lower extremities during 12 months after spinal cord injury measured by peripheral quantitative computed tomography. Spinal cord 2000; 38: 26-32.

21 Eser $\mathrm{P}$ et al. Relationship between the duration of paralysis and bone structure: a pQCT study of spinal cord injured individuals. Bone 2004; 34: 869-880.

22 Pacy PJ, Hesp R, Halliday DA, Katz D, Cameron G, Reeve J. Muscle and bone paraplegic patients, and effect of functional electrical stimulation. Clin Sci 1988; 75: 481-487.

23 Leduc BE, Lefebvre B, Puig P, Daigneault L. L'osteoporose sous-lesionnelle chez le blessé médullaire évaluée par ostéodensitométrie. Ann Readapt Med Phys 1991; 34: 199-204.

24 Kunkel CF, Scremin E, Eisenberg B, Garcia JF, Roberts S, Martinez S. Effect of 'standing' on spasticity, contracture, and osteoporosis in paralysed males. Arch Phys Med Rehab 1993; 74: 73-78. 
25 Thoumie $\mathrm{P}$ et al. Restoration of functional gait in paraplegic patients with the RGO-II hybrid orthosis. A multicenter controlled study. II: physiological evaluation. Paraplegia 1999; 533: 654-659.

26 Bedell KK, Scremin AME, Perell KL, Kunkel CF. Effects of functional electrical stimulation-induced lower extremity cycling on bone density of spinal cord-injured patient. $A m$ J Phys Med Rehab 1996; 75: 29-34.

27 Mohr T, Podenphant J, Biering-Sorensen F, Galbo H, Thamsborg G, Kjaer M. Increased bone mineral density after prolonged electrically-induced cycle training of paralyzed limbs in spinal cord injured man. Calcif Tissue Int 1997; 61: 22-25.

28 Pearson EG, Nance PW, Leslie WD, Ludwog S. Cyclical etidronate: its effect on bone density in patients with acute spinal cord injury. Arch Phys Med Rehab 1997; 78: 269-272.

29 Szollar SM et al. Bone mineral density and indexes of bone metabolism in spinal cord injury. Am J Phys Med Rehab 1998; 77: 28-35.

30 Wood DE, Dunkerley AL, Tromans AM. Results from bone mineral density scans in twenty-two complete lesion paraplegics. Spinal cord 2001; 139: 145-148.

31 Jones LM, Legge M, Goulding A. Intensive exercise may preserve bone mass of the upper limbs in spinal cord injured males but does not retard demineralisation of the lower body. Spinal Cord 2002; 40: 230-235.

32 Jaovisidha S, Sartoris DJ, Martin EME, De Maeseneer M, Szollar SM, Deftos LJ. Influence of spondylopathy on bone densitometry using dual energy X-ray absorptiometry. Calcif Tissue Int 1997; 60: 424-429.

33 Zerwekh JE, Ruml LA, Gottschalk F, Pack CYC. The effects of twelve weeks of bed rest on bone histology, biochemical markers of bone turnover, and calcium homeostasis in eleven normal subjects. $J$ Bone Miner Res 1998; 13: 594-1601.

34 Vico L et al. Effects of long-term microgravity exposure on cancellous and cortical weight-bearing bones of cosmonauts. Lancet 2000; 355: 1607-1611.

35 Chantraine A, Van Ouwenaller C, Hachen HJ, Schinas P. Intramedullary pressure and intra-osseous phlebography in paraplegia. Paraplegia 1979; 17: 108

36 Naftchi NE, Viau AT, Sell GH, Lowman EW. Pituitarytesticular axis dysfunction in spinal cord injury. Arch Phys Med Rehab 1980; 61: 402-405.

37 Bergmann P, Heilporn A, Schoutens A, Paternot J, Tricot A. Longitudinal study of calcium and bone metabolism in paraplegic patients. Paraplegia 1977-78; 15: 147-159.

38 Stewart AF, Adler MD, Byers CM, Segre GV, Broadus AE. Calcium homeostasis in immobilization: an example of resorptive hypercalciuria. $N$ Engl J Med 1982; 306: $1136-1140$.

39 Minaire P, Berard E, Meunier PJ, Edouard C, Goedert G, Pilonchery G. Effects of disodium dichloromethylene diphosphonate on bone loss in paraplegic patients. $J$ Clin Invest 1981; 68: 1086-1092.

40 Maynard FD. Immobilization hypercalcemia following spinal cord injury. Arch Phys Med Rehab 1986; 67: 41-44.

41 Elias AN, Gwinup G. Immobilization osteoporosis in paraplegia. J Am Paraplegia Soc 1992; 15: 163-170. Review.

42 Vaziri ND, Pandia MR, Segal JL, Winer RL, Eltari I, Brunneman S. Vitamin D, parathormone, and calcitonin profiles in persons with long-standing spinal cord injury. Arch Phys Med Rehab 1994; 74: 960-964.
43 Mechanick JI, Pomerantz F, Flanagan S, Stein A, Gordon WA, Ragnarsson KT. Parathyroid hormone suppression in spinal cord injury patients is associated with the degree of neurologic impairment and not the level of injury. Arch Phys Med Rehab 1997; 78: 692-696.

44 Maïmoun L et al. Use of bone biochemical markers with dual-energy X-ray absorptiometry for early determination of bone loss in persons with spinal cord injury. Metabolism 2002; 8: 958-963.

45 Uebelhart D, Hartmann D, Vuagnat H, Castagnier M, Hachen HJ, Chantraine A. Early modifications of biochemical markers of bone metabolism in spinal cord injury patients. A preliminary study. Scand J Rehab Med 1994; 26: 197-202.

46 Pietschmann P, Pils P, Woloszczuk W, Maerk R, Lessan $\mathrm{D}$, Stipicic J. Increased serum osteocalcin levels in patients with paraplegia. Paraplegia 1992; 30: 204-209.

47 Chantraine A, Nusgens B, Lapiere CM. Bone remodelling during the development of osteoporosis in paraplegia. Calcif Tissue Int 1986; 38: 323-327.

48 Demirel G, Yilmaz H, Paker N, Önel S. Osteoporosis after spinal cord injury. Spinal Cord 1998; 36: 822-825.

49 Bauman WA, Spungen AM, Wang J, Pierson RN, Schwartz E. Continuous loss of bone during chronic immobilization: a monozygotic twin study. Osteoporos Int 1999; 10: 123-127.

50 Lazo MG, Shirazi P, Sam M, Giobbie-Hurder A, Blacconiere MJ, Muppidi M. Osteoporosis and risk of fracture in men with spinal cord injury. Spinal Cord 2001; 39: $208-214$

51 Tsuzuku S, Ikegami Y, Yabe K. Bone mineral density differences between paraplegic and quadriplegic patients: a cross-sectional study. Spinal Cord 1999; 37: 358-361.

52 Finsen V, Indredavok B, Fougner KJ. Bone mineral and hormonal status in paraplegics. Paraplegia 1992; 30: 343-347.

53 Saltztein RJ, Hardin S, Hastings J. Osteoporosis in spinal cord injury: using an index of mobility and its relationship to bone density. J Am Paraplegia Soc 1992; 15: 232-234.

54 Sabo D, Blaich S, Wenz W, Hohmann M, Loew M, Gerner H. Osteoporosis in patients with paralysis after spinal cord injury. Arch Orthop Trauma Surg 2001; 121: 75-78.

55 Lee TQ, Shapiro TA, Bell DM. Biochemical properties of human tibias in long-term spinal cord injury. $J$ Rehab Res Dev 1997; 34: 295-302.

56 Ingram RR, Suman RK, Freeman PA. Lower limb fractures in the chronic spinal cord injured patient. Paraplegia 1989; 27: 133-139.

57 Keating JF, Kerr M, Delargy M. Minimal trauma causing fractures in patients with spinal cord injury. Disabil Rehab 1992; 14: 108-109.

58 Ragnarsson KT, Sell GH. Lower extremity fractures after spinal cord injury: a retrospective study. Arch Phys Med Rehab 1981; 62: 418-423.

59 Nottage WM. A review of long-bone fractures in patients with spinal cord injuries. Clin Orthop 1981; 155: 65-70.

60 Freehafer AA. Limb fractures in patients with spinal cord injury. Arch Phys Med Rehab 1995; 76: 823-827.

61 Moynahan M, Betz RR, Triolo RJ, Maurer AH. Characterisation of the bone mineral density of children with spinal cord injury. J Spinal Cord Med 1996; 19: 249-254.

62 Abramson AS, Delagi EF. Influence of weight-bearing and muscle contraction on disuse osteoporosis. Arch Phys Med Rehab 1961; 42: 147-151. 
63 Kaplan PE, Gandhavadi B, Richards L, Goldschmidt JW. Calcium balance in paraplegic patients: influence of injury duration and ambulation. Arch Phys Med Rehab 1978; 59: 447-450.

64 Kaplan PE, Roden W, Gilbert E, Richards L, Goldschmidt JW. Reduction of hypercalciuria in tetraplegia after weight-bearing and strengthening exercises. Paraplegia 1981; 19: 289-293.

65 Olgivie C, Bowker P, Rowley DI. The physiological benefits of orthotically-aided walking. Paraplegia 1993; 31: 11-113.

66 Needham-Shropshire BM, Broton JG, Klose KJ, Lebwohl $\mathrm{N}$, Guest RS, Jacobs PL. Evaluation of a training program for persons with SCI paraplegia using the Paratep ${ }^{\circledR} 1$ ambulation system: Part 3. Lack of effect on bone mineral density. Arch Phys Med Rehab 1997; 78: 799-803.

67 Goemare S, Van Laere M, De Neve P, Kaufman JM. Bone mineral status in paraplegic patients who do or do not perform standing. Osteoporosis Int 1994; 4: 138-143.

68 De Bruin ED, Frey-Rindova P, Herzog RE, Dietz V, Dambacher MA, Stussi E. Changes of tibia bone properties after spinal cord injury: effects of early intervention. Arch Phys Med Rehab 1999; 80: 214-220.

69 Rubin CT, Lanyon LE. Regulation of bone formation by applied dynamic loads. J Bone Joint Surg 1984; 66A: 397-402.

70 Rubin C et al. Quantity and quality of trabecular bone in the femur are enhanced by a strongly anabolic, noninvasive mechanical intervention. J Bone Miner Res 2002; 17: 349-357.

71 Verschueren S, Roelants M, Delecluse C, Swinnen S, Vanderschueren D, Boonen S. Effect of 6-month whole body vibration on hip density, muscle strength, and postural control in postmenopausal women: a randomised controlled pilot study. J Bone Miner Res 2004; 19: 352-359.

72 Morel J, Combe B, Francisco J, Bernard J. Bone mineral density of 704 amateur sportsmen involved in different physical activities. Osteoporos Int 2001; 12: 152-157.

73 Baldi JC, Jackson RD, Moraille R, Mysiw WJ. Muscle atrophy is preserved in patients with acute spinal cord injury using functional electrical stimulation. Spinal Cord 1998; 36: 463-469.

74 Scremin AME et al. Increasing muscle mass in spinal cord injured persons with a functional electrical stimulation exercise program. Arch Phys Med Rehab 1999; 80: 1531-1536.

75 Belanger M, Stein RB, Wheeler GD, Gordon T, Leduc B. Electrical stimulation: can it increase muscle strength and reverse osteopenia in spinal cord injured individuals? Arch Phys Med Rehab 2000; 81: 1090-1098.

76 Bloomfield SA, Mysiw WJ, Jackson RD. Bone mass and endocrine adaptations to training in spinal cord injured individuals. Bone 1996; 19: 61-68.

77 Leeds EM, Klose KJ, Ganz W, Serafini A, Green BA. Bone mineral density after bicycle ergometry training. Arch Phys Med Rehab 1990; 71: 207-209.

78 Rodgers MM et al. Musculoskeletal responses of spinal cord injured individuals to functional neuromuscular stimulation-induced knee extension exercise training. J Rehab Res Dev 1991; 28: 19-26.

79 Hangartner TN, Rodgers MM, Glaser RM, Barre PS. Tibial bone density loss in spinal cord injured patients. Effects of FES exercise. J Rehab Res Dev 1994; 31: 50-61.

80 Sloan KE, Bremner LA, Byrne J, Day R, Sculel ER. Muskuloskeletal effects of an electrical stimulation-induced cycling programme in spinal injured. Paraplegia 1994; 32: 407-415.

81 Eser P, De Bruin ED, Telley I, Lechner H, Knecht H, Stüssi E. Effect of electrical stimulation-induced cycling on bone mineral density in spinal cord-injured patients. Eur J Clin Invest 2003; 33: 412-419.

82 Minaire P. Immobilization osteoporosis: a review. Clin Rheumatol 1989; 8: 95-103.

83 Arai T, Ohashi T, Daitocch Y, Inoue S. The effect of ultrasound stimulation on disuse osteoporosis. Trans Bioelect Repair Growth Soc 1993; 13: 17.

84 Naruse K et al. Anabolic response of mouse bone-marrowderived stromal cell clonal ST2 cells to low-intensity pulsed ultrasound. Biochem Biophys Res Commun 2000; 268: 216-220.

85 Warden SJ, Bennell KL, Matthews B, Brown DJ, McMeeken JM, Wark JD. Efficacy of low-intensity pulsed ultrasound in the prevention of osteoporosis following spinal cord injury. Bone 2001; 29: 431-436.

86 Chambers TJ, Magnus CJ. Calcitonin alters behavior of isolated osteoclasts. J Pathol 1982; 136: 27-36.

87 Mac Donald BR, Takahashi N, McManus LM, Holahan J, Mundy GR, Roodman GD. Formation of multinucleated cells that respond to osteotropic hormones in long term human marrow cultures. Endocrinology 1987; 120: 2326-2333.

88 Mac Intyre I et al. Calcitonin for prevention of postmenopausal osteoporosis. Lancet 1988; I: 900-902.

89 Kanis JA et al. Evidence for efficacy of drugs affecting bone metabolism in preventing hip fracture. BMJ 1992; 305: 1124-1128.

90 Minaire $\mathrm{P}$ et al. Effect of clodronate on immobilisation bone loss. Bone 1987; 8: S63-S68.

91 Massagli TL, Cardenas DD. Immobilization hypercalcemia treatment with pamidronate disodium after spinal cord injury. Arch Phys Med Rehab 1999; 80: 998-1000.

92 Kedlaya D, Brandstater ME, Lee JK. Immobilization hypercalcemia in incomplete paraplegia: successful treatment with pamidronate. Arch Phys Med Rehab 1998; 79: 222-225.

93 Meythaler JM, Tuel SM, Cross LL. Successful treatment of immobilistion hypercalcemia using calcitonin and etidronate. Arch Phys Med Rehab 1993; 74: 316-319.

94 Chappard D et al. Effects of tiludronate on bone loss in paraplegic patients. J Bone Miner Res 1995; 10: 112-118.

95 Sniger W, Garshick E. Alendronate increases bone density in chronic spinal cord injury: a case report. Arch Phys Med Rehab 2002; 83: 139-140.

96 Zehnder Y et al. Prevention of bone loss in paraplegics over 2 years with alendronate. J Bone Miner Res 2004; 19: $1067-1074$. 